\title{
Erratum: Line Transect Sampling of Primates: Can Animal-to-Observer Distance Methods Work?
}

\author{
Stephen T. Buckland • Andrew J. Plumptre • \\ Len Thomas • Eric A. Rexstad
}

Published online: 2 December 2010

(C) Springer Science+Business Media, LLC 2010

\section{Erratum to: Int J Primatol (2010) 31:485-499 \\ DOI 10.1007/s10764-010-9408-4}

The authors of the above paper would like to correct the page numbers of one of the references. The correct reference for Marshall et al. (2008) is as follows:

Marshall, A. R., Lovett, J. C., \& White, P. C. L. (2008). Selection of line-transect methods for estimating the density of group-living animals: lessons from the primates. Am J Primatol, 70,452-462.

The online version of the original article can be found at http://dx.doi.org/10.1007/s10764-010-9408-4.

S. T. Buckland $(\bowtie) \cdot$ L. Thomas $\cdot$ E. A. Rexstad

Centre for Research into Ecological and Environmental Modelling, University of St. Andrews,

The Observatory, St. Andrews, Fife KY16 9LZ, UK

e-mail: steve@mcs.st-and.ac.uk

\section{A. J. Plumptre}

Wildlife Conservation Society, PO Box 7487, Kampala, Uganda 